\title{
Targeting Individuals with Problematic Alcohol Use via Web-Based Cognitive-Behavioral Self-Help Modules, Personalized Screening Feedback or Assessment Only: A Randomized Controlled Trial
}

\author{
Kristina Sinadinovic $^{a, c}$ Peter Wennberg ${ }^{b, d}$ Magnus Johansson ${ }^{c}$ \\ Anne H. Berman a, c \\ ${ }^{a}$ Center for Psychiatric Research, Department of Clinical Neuroscience, and ${ }^{b}$ Division of Social Medicine, Department of \\ Public Health, Karolinska Institutet, ' Stockholm Center for Dependency Disorders, and ${ }^{\mathrm{d}}$ Center for Social Research on \\ Alcohol and Drugs, Stockholm University, Stockholm, Sweden
}

\section{Key Words}

Randomized controlled trial · Alcohol · Internet .

Screening · Brief interventions · Personalized feedback ·

Cognitive-behavioral treatment program

\begin{abstract}
Background/Aims: Most problematic alcohol users never seek professional help to reduce their use, and Web-based interventions might fulfill users' unmet needs for professional support. Methods: This randomized controlled trial compared two open Web-based interventions, one extended self-help program and one brief screening and feedback intervention, with an assessment-only control group. Participants were 633 Internet help seekers with at least hazardous alcohol use (Alcohol Use Disorders Identification Test, AUDIT $\geq 6$ for women and $\geq 8$ for men). Results: All groups reduced their alcohol use at 3-month follow-up $(p<0.001)$, remaining stable at the 6- and 12-month follow-ups (n.s.) according to AUDIT-C and AUDIT scores (intention-to-treat, $\mathrm{ITT}$, analysis). Per protocol (PP) analysis, including only participants who accessed the interventions and also reported accessing additional outside interventions during the trial, showed that about $75 \%$ of extended self-help participants moved from probable dependence, harmful or hazardous
\end{abstract}

use to lower alcohol use levels at 3- and 6- and 12-month follow-ups, compared to about $40-60 \%$ of brief intervention users and controls who accessed extra help $(p<0.05)$. Conclusion: ITT analysis suggested parity over time for all interventions, including assessment only, in reducing problematic alcohol use. In contrast, PP analysis suggested that cognitive-behavioral extended self-help in combination with other interventions was more effective in changing alcohol use than brief intervention or assessment only.

(C) 2014 S. Karger AG, Basel

\section{Introduction}

Excessive consumption of alcohol is one of the leading risk factors causing disability-adjusted life years and death all over the world [1]. It is well established that screening and brief intervention provided by professional treatment providers can effectively reduce problematic alcohol use [2-4] and can be just as effective as longer interventions [5]. However, it is also well established that only a small proportion of problematic alcohol users ever seek professional help [6,7], often because of shame, fear of stigmatization, and the will to resolve the problem without external help [8-10]. Over the past decade, treat-

\begin{tabular}{ll}
\hline KARGER & $\begin{array}{l}\text { ( ) 2014 S. Karger AG, Basel } \\
1022-6877 / 14 / 0206-0305 \$ 39.50 / 0 \quad \text { Karger }\end{array}$ \\
$\begin{array}{l}\text { E-Mail karger@karger.com } \\
\text { www.karger.com/ear }\end{array}$ & $\begin{array}{l}\text { This is an Open Access article licensed under the terms of the } \\
\text { Creative Commons Attribution-NonCommercial 3.0 Un- } \\
\text { ported license (CC BY-NC) (www.karger.com/OA-license), } \\
\text { applicable to the online version of the article only. Distribu- } \\
\text { tion permitted for non-commercial purposes only. }\end{array}$
\end{tabular}

Anne H. Berman, PhD

Karolinska Institutet, Department of Clinical Neuroscience

Center for Psychiatric Research

Norra Stationsgatan 69, 7th floor, SE-113 64 Stockholm (Sweden)

E-Mail anne.h.berman@ki.se 
ment providers and policy makers have increasingly recognized the potential of Web-based self-help for fulfilling problematic alcohol users' unmet needs for professional interventions.

The research field of Web-based interventions for reducing problematic alcohol use is still young, including relatively few randomized controlled trials (RCTs) examining the effects of such interventions targeting adults from the general population [11-14]. Vernon [15] identified 8 studies evaluating the effects of online and offline intervention programs for reducing alcohol use among adults (5 targeting members of the general population and 3 conducted through the workplace). All but one of the included studies showed a decrease in alcohol use, with effect sizes ranging from 0.40 to 2.36 ; however, the differences in interventions, outcome measures and methodological designs between the studies make the effect sizes very difficult to compare. Categorizing Internetbased interventions in terms of content could be one way to facilitate such comparison.

Cunningham et al. [16] divided Web-based interventions for problematic alcohol use into: (1) screeners, brief interventions usually containing an assessment questionnaire which takes up to $10 \mathrm{~min}$ to complete and generates feedback that is personalized for the user, and (2) cognitive-behavioral treatment (CBT) programs often containing several modules and designed for use on several occasions. Riper et al. [17] use same categories but describe them as single-session personalized normative feedback interventions and extended self-help interventions. Below, we briefly summarize research results concerning screeners (Cunningham and colleagues' definition) and, separately, extended self-help interventions (Riper and colleagues' definition).

The first single-session personalized normative feedback intervention for alcohol use designed for use in a general population and evaluated in a RCT was www. CheckYourDrinking.net. Results showed a significantly larger decrease in alcohol consumption for the screener users compared to an assessed control group at the 3 - and 6-month follow-ups [18]. However, these effects were no longer noticeable at the 12-month follow-up [19]. The effects of this intervention were also evaluated among young working people 18-24 years old. In a randomized trial, users were compared to individuals who received a 15-min face-to-face motivational interviewing (MI) session in addition to accessing the screener; both groups were compared with an assessed control group. At a 30day follow-up, a significantly larger decrease in alcohol use was found for the two groups that used the screener compared to the untreated control group. Further, no differences in the decrease in alcohol use were found between the group using only the screener and the group that additionally received the face-to-face MI session [20]. More recently, a Dutch single-session personalized normative feedback intervention, www.Drinktest.nl, was found to be more effective in reducing problematic alcohol consumption than a brochure with facts about alcohol. However, 3-month follow-up effects were not sustained at 6 months [21]. Hansen et al. [22] also tested the effects of a Web-based brief personalized feedback intervention in a general population-based sample of heavy drinkers. Results without the imputation of missing data showed some indications that the intervention was effective in reducing drinking. However, these results were not confirmed in intention-to-treat (ITT) analyses.

The effects of Web-based extended self-help interventions without any support from a human therapist have been tested in several RCTs showing promising results. The Dutch online CBT-based program 'Self-help alcohol online' proved more effective at the 3-month follow-up for reducing alcohol use than the assessment-only condition that served as a control group. Also, the self-help program was equally effective as therapist-supported selfhelp. However, at the 6-month follow-up, the intervention including therapist contact was more effective than the self-help online intervention without such contact [23]. Another Dutch online CBT-based program, freely available to the general population at www.minderdrink en.nl, was more effective at the 6-month follow-up than a general Internet site with psychoeducational information on the effects of using alcohol $[24,25]$. In contrast, a British online CBT-based program, freely available at www.downyourdrink.org.uk, was shown to be as effective in reducing alcohol use as a general psychoeducational information site [26]. Two US online extended self-help interventions, www.moderatedrinking.com and www. moderation.org, both targeting the general adult population, showed that both sites in combination were more effective at 3-, 6- and 12-month follow-ups than using www.moderation.org alone $[27,28]$.

Some of these studies $[18,20,21,25]$ were included in a meta-analysis conducted by Riper et al. [17], who compared the effects of single-session personalized normative feedback interventions (5 studies) with the effects of extended self-help interventions (4 studies) targeting adult problem drinkers. Nine RCTs were included, involving both offline and online computerized interventions. Excluding 2 studies as outliers, the mean effect size of the single-session interventions was found to be $g=0.27$ 
compared to the mean effect size of the extended self-help interventions, which was $g=0.61$ [17]. At this writing, only one randomized trial has compared the efficacy of a Web-based personalized normative feedback intervention with an extended Web-based intervention without therapist support in the general population. Findings showed that the extended intervention was more effective for reducing alcohol consumption than the brief one [29].

The aim of this three-armed RCT was to compare an online personalized normative feedback intervention, eScreen.se, to a CBT-based online extended self-help intervention, Alkoholhjalpen.se, among individuals in the general population seeking help for problematic alcohol use. Both these interventions were compared with a control group that received Web-based assessment only. Based on previous research, we hypothesized that use of the brief intervention and the extended CBT-based selfhelp program would both be associated with a larger decrease in alcohol use than Web-based assessment only. Our secondary hypothesis was that use of the extended CBT-based self-help program would be associated with a larger decrease in alcohol use than use of the brief intervention. Both ITT and per-protocol (PP) analyses are presented.

\section{Materials and Methods}

\section{Trial Recruitment and Procedure}

Participant recruitment for this three-armed parallel randomized study began on September 22, 2009, via links on alcohol- and drug-related Internet sites. Due to slow recruitment during the first 3 months, the recruitment procedure was extended to include Google ads for individuals seeking online information about alcohol and drug problems. Trial recruitment ended on November 7, 2010. Self-selected individuals interested in participating clicked on a link to the study registration site. After informed consent, baseline information was collected about gender, year of birth, problematic alcohol use based on the Alcohol Use Disorders Identification Test (AUDIT) developed by the World Health Organization [30], and problematic drug use based on the Drug Use Disorders Identification Test (DUDIT) [31], an 11-item questionnaire screening for problematic drug use developed by the senior author (A.H.B.) and currently available in numerous languages (see http://www.emcdda.europa.eu/html.cfm/index10451EN.html). In addition, participants answered health-related questions covering general health, sleep quality, concentration ability, pain, stress, etc. Participants provided an e-mail address for communication purposes. All data were stored in a secure database available only to the research team.

Eligible individuals had at least hazardous alcohol use (AUDIT $\geq 6$ for women and $\geq 8$ for men) and no illicit drug use (DUDIT $=$ $0)$. Individuals who used drugs, with or without problematic alcohol use, were referred to a parallel study targeting drug users [32, 33]. To be included in the trial, individuals also needed to have adequate computer skills. We assumed that searching for information about alcohol or drugs via the Internet, responding to the study advertisement and completing study registration online indicated such skills.

Participants needed to be 15 years or older. This age limit was set based on Section 18 of the Swedish Act on Ethical Review of Research Involving Humans (2003:460), which allows individuals 15 years and older to participate in research studies without parental consent. In total, 3 individuals $(0.47 \%)$ were under 18 years of age. Excluded individuals were informed that their substance use was assessed as nonproblematic, and they were provided with a link to an informational site about alcohol and its effects.

A computer-generated list of random numbers in blocks of 25 was created with GraphPad Software [34], and pre-programmed by a technician into a fully automated allocation system on the study registration Web site. Study participants were randomly assigned to one of three parallel groups in a 1:1:1 ratio. After randomization, each participant received an e-mail with information on the condition he or she was assigned to. Participants in the intervention groups received identical instructions, a link to the appropriate intervention and follow-up information. Participants in the control group were sent information on follow-ups after 3, 6 and 12 months, along with a statement that 'earlier research has shown that responding to such questions has an effect on reduction of risky alcohol or drug use'. Participants were randomized into the following groups: (1) referral to eScreen.se $(n=211$, $33.3 \%)$; (2) referral to Alkoholhjalpen.se ( $\mathrm{n}=212,33.5 \%)$; or (3) an assessment-only control group $(n=210,33.2 \%)$. The entire trial, including recruitment, registration for the trial, allocation to the interventions, use of interventions, as well as the baseline and follow-up assessments, was conducted online. Both interventions were open-ended, meaning that participants could log on as often as they wanted and for as long as they wanted, even after the end of the trial. Logging on at an intervention site was established as an indicator that a participant used the corresponding intervention. Participants allocated to Alkoholhjalpen.se logged onto the service to a somewhat lesser extent $(\mathrm{n}=114 ; 53.7 \%)$ than those allocated to eScreen.se ( $n=152,72 \%$; see fig. 1 ). Regarding response rates to follow-up e-mails, the total attrition rate for the 3-month followup was $62.1 ; 64.8 \%$ for the 6 -month follow-up and $55.3 \%$ for the 12 -month follow-up. Study participants were not given any instructions to steer their utilization of other online services and no compensation was given for trial participation. A detailed flowchart for the trial is shown in figure 1 .

The study was positively reviewed by the Stockholm Regional Ethical Review Board (No. 2008/308-31/5) and the trial was registered at ClinicalTrials.gov (No. 2008/308-31/5A).

\section{Interventions}

eScreen.se

Participants in this arm of the trial were e-mailed a link to a free, publicly available brief intervention, eScreen.se (www.escreen.se). They were able to log on and access the intervention with a personal user name and a password that they created when they registered for the study. Via e-mail, the participants were also informed that they were free to use the intervention as often and as long as they wished, meaning that there was no recommended time for using the intervention as well as no end to the intervention. eScreen. se is a brief personalized normative feedback intervention aiming to reduce both problematic alcohol use as well as problematic drug 


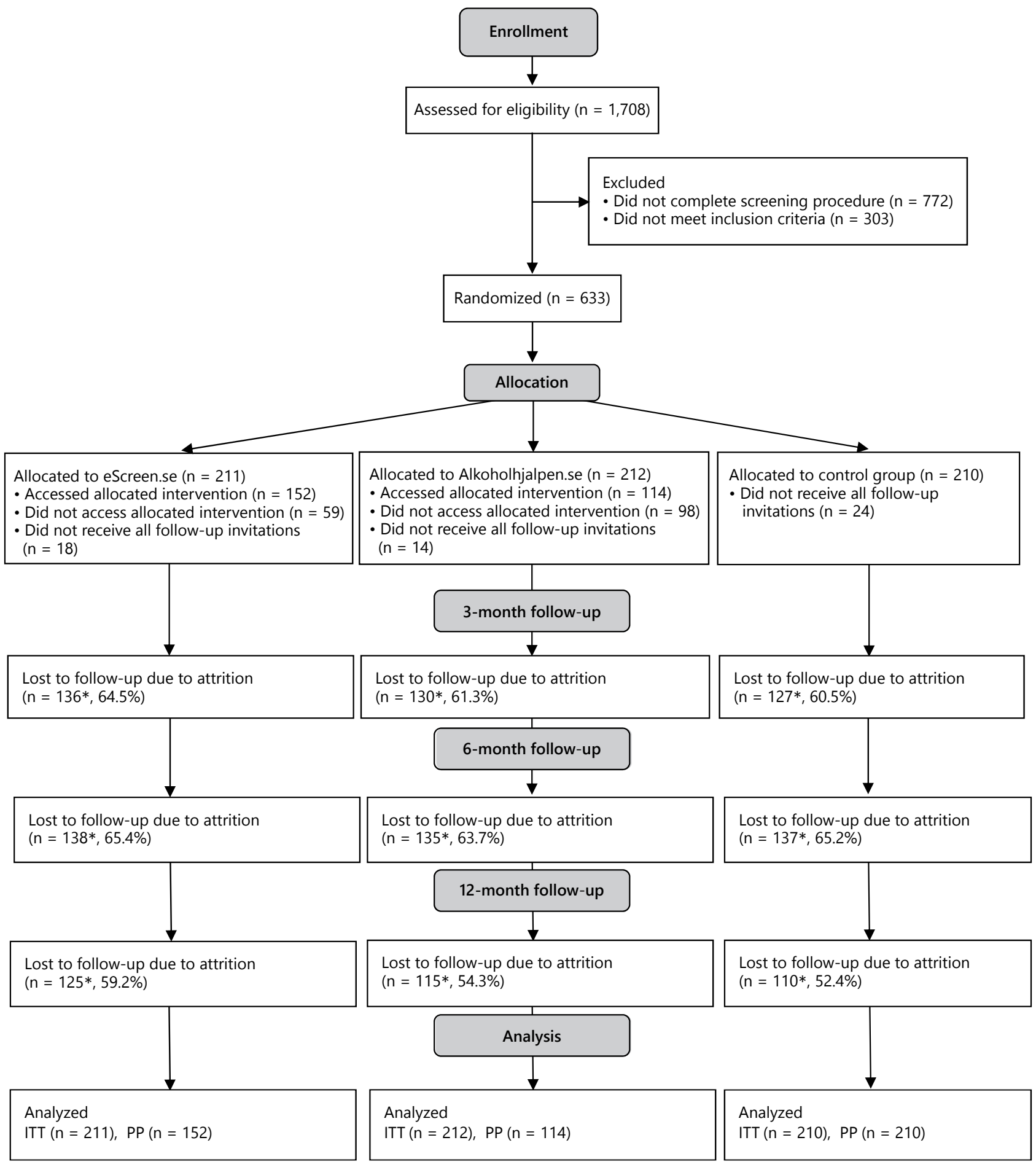

Fig. 1. Flowchart for trial participants. Asterisk means attrition is not cumulative. ITT analysis included all allocated individuals. $\mathrm{PP}$ analysis included only those individuals from intervention groups that accessed the intervention and the entire control group. 
use; it offers two short instruments assessing alcohol (AUDIT) and illicit drug use (DUDIT), with 10 and 11 items, respectively. Also, two in-depth self-report instruments - Alcohol-E (for alcohol) and the Drug Use Disorders Identification Test-Extended (DUDIT-E, for illicit drugs), with 54 items each [35-37] - are offered at the Web site to help users explore the role of substances in their lives as well as readiness to change. Completion of each of the four assessment instruments generates personalized normative feedback, as well as graphs showing the severity of substance use, with normative comparison to similar gender and age groups. The written feedback is based on the principles of MI [38] and basically consists of reflective statements based on the respondents' own answers to the assessment questions. For the in-depth Alcohol-E and DUDIT-E tests, the feedback includes a summary of the positive and negative aspects of alcohol or drug use indicated by the users, sorted according to categories originally determined via factor analysis; the feedback also describes the individual's phase in the process of behavioral change, based on a motivational index algorithm [36]. Following the personalized questionnaire feedback, behavioral recommendations are given in the spirit of MI, primarily suggesting in nonconfrontational language that individuals talk to someone about their problematic alcohol or drug use and return to the Web site for regular reassessment of their substance use. Based on the assumption that more severe use increases the risk of negative health consequences, the more severe the identified substance use, the more frequently the individual is recommended to return to the site. This recommendation is made for clinical and research-based ethical reasons. The recommendations are adapted for adolescents as well as adults and are based on information in the combined AUDIT and DUDIT manual as well as current clinical practice [39]. The site also includes an electronic diary where the user can write about his or her recovery process or, indeed, about any topic of preference, since expressive writing has generally been found to positively affect physical and mental health [40]. Finally, the site also offers a list of resources covering national and local professional treatment resources as well as voluntary organizations offering support to problematic substance users. All entries are saved in a personal user account, making it possible to follow changes in substance use over time. The site can be accessed at any time, as many times as the user wishes.

\section{Alkoholhjalpen.se}

Participants in this intervention arm were e-mailed a link to Alkoholhjalpen.se (www.alkoholhjalpen.se), a free public site focusing on problematic alcohol use and providing CBT- and MIbased self-help with a solution-oriented focus. This intervention consists of 18 modules: Risk situations, Diary, Consequences, Progress rating scale, Decisional balance, Paths to change drinking, Formulating goals, Problem solving, New solutions, Things that already work, Miracle question, Friends and family, Other support/treatment, Alcohol refusal skills, Coping with cravings, Coping with thoughts, Related problems and Relapse prevention. Each module includes psychoeducational texts, interactive exercises and videos describing the rationales for the exercises. User responses to electronic questionnaires in each module generate personalized recommendations on which modules to work with next. However, all modules are freely available to the users, who can choose whichever modules they want to work with at their own discretion, in the order they wish. Users follow their own progress over time by writing in an electronic diary. The intervention also contains an open discussion forum where users can interact with each other.

In the initial e-mail containing the link to Alkoholhjalpen.se, study participants were informed that they were free to use the intervention as often and as long as they wished but also that they should $\log$ on to the site with their personal user name and password. Since the site was also freely available without logging on, this procedure was intended to ensure that user-provided information would be saved in an account and linked to study participants. However, given that the site was publicly available, it was also possible for participants to use the intervention without logging on, in which case user data were not retained.

\section{Control Group}

Via e-mail, study participants allocated to the control group were informed that they would be contacted after 3, 6 and 12 months to provide information about their alcohol use and health status.

\section{Definitions}

Definitions of alcohol use levels were derived from the total AUDIT score, based on the Swedish AUDIT manual. A score in the range of $0-5$ for women and $0-7$ for men indicated nonproblematic alcohol use, 6-15 points for women and 8-15 points for men indicated hazardous alcohol use, $16-19$ points for both genders indicated harmful alcohol use and $20-40$ points for both genders indicated probable dependence on alcohol [39]. In this article, the term problematic alcohol use includes hazardous and harmful use as well as probable dependence. Each individual was assigned to an alcohol use level category based on his or her AUDIT score, at baseline and follow-up time points. A clinically significant change in the level of alcohol use was defined as moving from one alcohol use category at baseline to another category at follow-up.

\section{Outcome Measures}

The primary outcome measure was the total AUDIT-C score measuring current alcohol consumption at the 3-, 6- and 12-month follow-ups [41]. Secondary outcome measures were: (1) the total AUDIT score, measuring current alcohol consumption (items 1-3) and 12-month alcohol-related problems (items 4-10); (2) the percentage of participants who had reduced their alcohol use to a nonproblematic level, and (3) the percentage of participants who reduced their alcohol use to a clinically lower level of use, whether or not their use declined below the limit for nonproblematic use. The primary and secondary measures were all derived from the 10-item AUDIT questionnaire and instructions to the study participants were identical at each follow-up occasion.

\section{Follow-Ups}

An e-mail was sent to all study participants 3, 6 and 12 months after study recruitment, inviting them to click on a link that redirected them to the follow-up site with the AUDIT and health-related questions. At the 12-month follow-up, participants were asked to provide information about any interventions, other than the one they were assigned to, which they had accessed over the past year for their problematic alcohol use. Due to technical difficulties, no reminder was sent at the 3-and 6-month follow-ups, and only one reminder e-mail was sent at the 12-month follow-up to participants who did not respond to the follow-up invitation within 2 weeks after the exact 12-month follow-up date. For pur- 
poses of analysis, valid follow-up data were defined as responses to a follow-up invitation within a period of 31 days prior to or following the exact PP follow-up date.

\section{Power Analysis and Sample Size}

Prior to study recruitment, a power analysis was conducted with the GPower 3.1 program [42], based on a repeated measures analysis of variance design with 3 groups and 4 measurement occasions (baseline, 3, 6 and 12 months). At an a-level of 0.05 and power of 0.80 , a total sample size of 345 individuals was needed for detection of an effect size of $f(V)=0.20$. Based on the high attrition rates reported in previous research on Internet-based interventions $[23,26]$, the decision was made to recruit as many study participants as possible between September 22, 2009 and November 7,2010 , even after the number of participants needed according to the power analysis had been exceeded.

\section{Analyses}

Missing Data

Where possible, missing values were imputed with last observation carried backwards (LOCB). In this way, missing data were imputed with participants' actual data from a later occasion rather than assuming no change in behavior. In cases where no followup data at all were available, the last observation was carried forward (LOCF), treating the specific follow-up value as unchanged. Using both these two imputation methods meant that participants' actual data could be used to a greater extent than if one imputation method had been chosen. Thus, both data originating from different follow-up occasions and data originating from responses received between the different follow-up occasions were utilized; the latter could also have included late responses to follow-up e-mails. An alternative would have been to estimate data based on the relatively small proportion of the participants who participated in the follow-ups on time. Imputation by estimation would have meant that less authentic user data would have been used in the analyses. Given the large attrition rates at follow-ups, we considered it preferable to use authentic data rather than imputed data and have therefore used LOCB and LOCF to replace missing data. If the effects of the tested interventions are expected to appear first at later follow-up occasions, a limitation in replacing missing values with LOCB could be an exaggeration of the effects of the tested interventions. Since previous research in the area of Internet-based interventions has shown that the largest decrease in alcohol consumption (for both the intervention groups and controls) appears in the first 3 months and usually stabilizes thereafter $[18,21,23,26-28]$, we did not expect the LOCB procedure to cause an exaggeration of the intervention effects. We rather see this method as conservative since research has shown that alcohol consumption in the intervention group actually can increase after 6 months [19]. For LOCF, the limitation in replacing missing values is that treating alcohol use as unchanged from one time point to the next could exaggerate the effects of the intervention, since controls appear to have maintained a high level of alcohol use between the time points. However, previous research has shown a decrease in alcohol use among participants allocated to the control group. This decrease can also be assumed to occur in the intervention group. Since LOCF was used to the same extent for both the controls and the intervention groups, no bias to the advantage or disadvantage of the intervention group occurred.
Statistical Analysis

Both AUDIT and AUDIT-C scores at all time points had skewness values of well under 1.0 in absolute value and were therefore assumed to be reasonably normally distributed. These variables were not transformed. To investigate possible bias due to not accessing the allocated intervention, statistical analyses were conducted according to two different models of analysis: (1) ITT analyses, including all allocated individuals, both those who accessed the interventions as well as those who never did so; and (2) PP analyses including only those individuals from intervention groups that actually accessed the intervention. The control group was exactly the same for both ITT and PP analyses (tables 1-3). Missing data were handled as described above for both the ITT and PP analyses (tables 1-4).

Data were analyzed with MANCOVA, using AUDIT-C and the total AUDIT scores from 3-, 6- and 12-month follow-ups as dependent variables. Covariates entered into the model were corresponding baseline AUDIT-C and AUDIT scores as well as the variables measuring specific additional help accessed during the study and assessed at the 12-month follow-up (e.g. whether study participants talked to someone about their problematic alcohol use, whether they used any medication for their alcohol use and whether they used any Web-based services other than the one they had been randomized to, any telephone helplines or any written material in order the change their alcohol use). Paired t tests were used for post hoc comparisons (table 2). The $\chi^{2}$ test was used to analyze differences between the groups in proportions of individuals with varying levels of alcohol use (table 3 ). The $\chi^{2}$ test was also used to compare clinically significant changes in levels of alcohol use between study participants who had accessed any other intervention aside from the one they were allocated to, and participants who did not access any additional intervention (table 4).

\section{Results}

\section{Baseline Characteristics}

Baseline characteristics for individuals included in the ITT and PP models are shown in table 1. For the ITT model, which included all recruited participants, over half were women (54.3-55.7\%), the mean age was 44 years for all three randomization arms, and the mean AUDIT score varied between 20.1 and 21.5 points for all three conditions. The proportion of participants with probable alcohol dependence ( $\geq 20$ AUDIT points) ranged between 52.4 and $58.8 \%$. No statistically significant differences in baseline characteristics occurred between the randomization groups in either the ITT or PP model.

\section{Alcohol Consumption and Alcohol-Related Problems at Follow-Up}

Table 2 shows AUDIT-C and AUDIT scores, measured at baseline, 3-, 6- and 12-month follow-ups; see table 2 . In both models, statistically significant decreases in AUDIT-C and total AUDIT scores over time occurred in 
Table 1. Baseline characteristics of the trial participants by analysis model and intervention group

\begin{tabular}{|c|c|c|c|c|}
\hline & eScreen.se & Alkoholhjalpen.se & Control & $\mathrm{p}$ \\
\hline ITT model & $\mathrm{n}=211$ & $\mathrm{n}=212$ & $\mathrm{n}=210$ & \\
\hline Women, \% & 55.0 & 55.7 & 54.3 & $\left(\chi^{2}\right) 0.961$ \\
\hline Mean age & $44.0(42.2-45.9)$ & $43.8(42.1-45.4)$ & $44.1(42.5-45.2)$ & (F) 0.955 \\
\hline $\mathrm{SD}$ & 13.6 & 11.9 & 12.1 & \\
\hline Mean AUDIT score & $21.5(20.5-22.4)$ & $20.1(19.2-21.0)$ & $20.9(19.9-21.8)$ & (F) 0.111 \\
\hline Mean AUDIT-C score & $8.2(7.9-8.4)$ & $8.0(7.7-8.2)$ & $8.2(7.7-8.5)$ & (F) 0.390 \\
\hline Hazardous alcohol use, $\%$ & 22.3 & 25.5 & 23.3 & \\
\hline Harmful alcohol use, $\%$ & 19.0 & 22.2 & 19.0 & $\left(\chi^{2}\right) 0.725$ \\
\hline Probable alcohol dependence, $\%$ & 58.8 & 52.4 & 57.6 & \\
\hline PP model & $\mathrm{n}=152$ & $\mathrm{n}=114$ & $\mathrm{n}=210$ & \\
\hline Women, \% & 54.6 & 57.0 & 54.3 & $\left(\chi^{2}\right) 0.887$ \\
\hline Mean age & $44.6(42.4-46.8)$ & $43.0(40.9-45.6)$ & $44.1(42.5-45.7)$ & (F) 0.707 \\
\hline $\mathrm{SD}$ & 13.7 & 12.7 & 12.1 & \\
\hline Mean AUDIT score & $21.2(20.1-22.2)$ & $19.4(18.2-20.5)$ & $20.9(19.9-21.8)$ & (F) 0.068 \\
\hline Mean AUDIT-C score & $8.1(7.8-8.4)$ & $7.8(7.2-7.9)$ & $8.2(7.9-8.5)$ & (F) 0.243 \\
\hline Hazardous alcohol use, $\%$ & 22.4 & 26.3 & 23.3 & \\
\hline Harmful alcohol use, $\%$ & 20.4 & 25.4 & 19.0 & $\left(\chi^{2}\right) 0.515$ \\
\hline Probable alcohol dependence, $\%$ & 57.2 & 48.2 & 57.6 & \\
\hline
\end{tabular}

Figures in parentheses indicate range unless otherwise indicated.

all groups at the 3-month follow-up $(\mathrm{p}<0.001)$. The level of alcohol use remained relatively stable in all groups at the 6- and 12-month follow-ups. These results were the same for both the ITT and the PP models.

In the PP model, we found one significant difference between the groups, where those who accessed Alkoholhjalpen.se had a lower AUDIT-C score at 6-month follow-up than those who accessed eScreen.se $(\mathrm{p}=0.048)$, but not at 12-month follow-up.

Proportions of participants that changed to a clinically different level of alcohol use at 3, 6 and 12 months' followup are presented in table 3 .

\section{Access to Additional Interventions during the Study Period}

For a deeper understanding of our results, it is important to take into account any other interventions study participants might have accessed while participating in the study. Differences in the proportions of participants in the PP model who made a clinically significant change in their level of alcohol use are presented in table 4, according to whether or not they accessed 'any other intervention'. The 'any other intervention' variable included speaking to someone, using medication, use of Internet services other than the one they were randomized to, use of telephone services or written materials during the study period.

Targeting Problematic Alcohol Use with Web-Based Interventions
Among those who accessed any other intervention, a significantly larger proportion of those who accessed Alkoholhjalpen.se changed to a lower consumption category, in comparison to those who accessed eScreen.se or were allocated to the control group. This difference was found at both the 3 -month (76.5 vs. 45.5 and 52.5\%) and 6-month follow-ups (73.5 vs. 40.9 and $57.6 \%)$ but was not maintained at the 12-month follow-up. However, at the 12-month follow-up, a significantly smaller proportion of those who accessed Alkoholhjalpen.se had unchanged levels of alcohol use in comparison to the controls ( 20.6 vs. $45.8 \%$ ). Results also showed that significantly larger proportion of those who accessed Alkoholhjalpen.se or eScreen.se changed to a higher consumption category at the 6-month follow-up compared to the controls (2.9 and 9.1 vs. $0 \%$ ). An additional result of interest (not shown in the tables) is that those who accessed eScreen.se indicated that they spoke to someone about their problematic use to a significantly larger extent $(70.1 \%)$ than those who accessed Alkoholhjalpen.se and controls [49.5 and 56.3\% respectively; $\left.\mathrm{p}\left(\chi^{2}\right)=0.028\right]$.

Among those who did not indicate accessing any intervention other than the one they were randomized to in this trial, significant differences between the groups were only found regarding changes to a higher consumption category at 6-month and 12-month follow-ups, where 
Table 2. Differences over time between the groups in mean AUDIT-C and total AUDIT scores when controlling for baseline differences in alcohol use and access to other interventions during study period

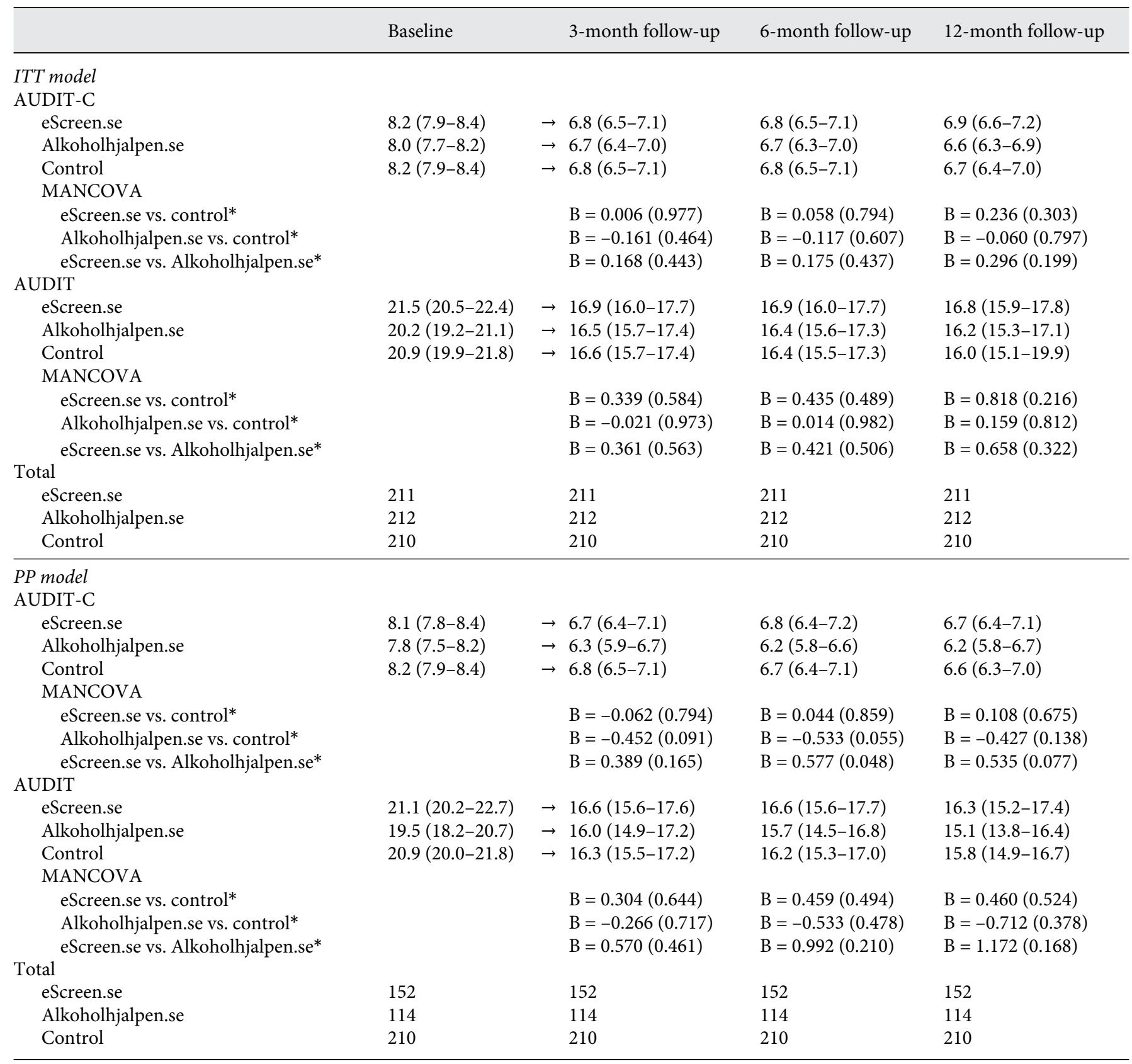

* Arrow indicates a significant difference according to paired t tests. Asterisk indicates reference group. Figures in parentheses indicate range (95\% Confidence Interval) or p value.

participants in the Alkoholhjalpen.se group differed significantly from the control group, in that none of the control group participants changed to a higher category, whereas $3.8 \%$ of the Alkoholhjalpen.se group did so at 6 and 12 months.
In the ITT model (not shown in the tables) only one significant difference between the groups was found. At the 6-month follow-up, $11.5 \%$ of the participants in the eScreen.se group who had accessed any other intervention during the study period had changed to a higher con- 
Table 3. Proportions (\%) of participants who changed to a clinically different level of alcohol use at 3-, 6- and 12-month follow-up

\begin{tabular}{|c|c|c|c|c|}
\hline & eScreen.se & Alkoholhjalpen.se & Control & $\mathrm{p}$ \\
\hline ITT model & $\mathrm{n}=211$ & $\mathrm{n}=212$ & $\mathrm{n}=210$ & \\
\hline \multicolumn{5}{|l|}{ At 3-month follow-up } \\
\hline Nonproblematic alcohol use & $10.4^{\mathrm{a}}$ & $10.8^{\mathrm{a}}$ & $11.0^{\mathrm{a}}$ & \multirow[t]{2}{*}{$\left(\chi^{2}\right) 0.983$} \\
\hline Lower level of alcohol use ${ }^{1}$ & $34.1^{\mathrm{a}}$ & $39.2^{\mathrm{a}}$ & $36.2^{\mathrm{a}}$ & \\
\hline Unchanged level of alcohol use & $64.9^{\mathrm{a}}$ & $59.9^{\mathrm{a}}$ & $63.3^{\mathrm{a}}$ & \multirow[t]{2}{*}{$\left(\chi^{2}\right) 0.950$} \\
\hline Higher level of alcohol use & $0.9^{\mathrm{a}}$ & $0.9^{\mathrm{a}}$ & $0.5^{\mathrm{a}}$ & \\
\hline \multicolumn{5}{|l|}{ At 6-month follow-up } \\
\hline Nonproblematic alcohol use & $11.4^{\mathrm{a}}$ & $12.3^{\mathrm{a}}$ & $11.4^{\mathrm{a}}$ & \multirow[t]{2}{*}{$\left(\chi^{2}\right) 0.305$} \\
\hline Lower level of alcohol use ${ }^{1}$ & $31.3^{\mathrm{a}}$ & $38.2^{\mathrm{a}}$ & $37.1^{\mathrm{a}}$ & \\
\hline Unchanged level of alcohol use & $64.5^{\mathrm{a}}$ & $59.4^{\mathrm{a}}$ & $62.9^{a}$ & \multirow[t]{2}{*}{$\left(\chi^{2}\right) 0.029$} \\
\hline Higher level of alcohol use & $4.3^{\mathrm{b}}$ & $2.4^{\mathrm{b}}$ & $0.0^{\mathrm{a}}$ & \\
\hline \multicolumn{5}{|l|}{ At 12 -month follow-up } \\
\hline Nonproblematic alcohol use & $11.4^{\mathrm{a}}$ & $13.7^{\mathrm{a}}$ & $16.2^{\mathrm{a}}$ & \multirow{2}{*}{$\left(\chi^{2}\right) 0.357$} \\
\hline Lower level of alcohol use ${ }^{1}$ & $31.3^{\mathrm{a}}$ & $39.2^{\mathrm{a}}$ & $37.1^{\mathrm{a}}$ & \\
\hline Unchanged level of alcohol use & $65.4^{\mathrm{a}}$ & $57.5^{\mathrm{a}}$ & $62.9^{\mathrm{a}}$ & \multirow[t]{2}{*}{$\left(\chi^{2}\right) 0.040$} \\
\hline Higher level of alcohol use & $3.3^{\mathrm{b}}$ & $3.3^{\mathrm{b}}$ & $0.0^{\mathrm{a}}$ & \\
\hline PP model & $\mathrm{n}=152$ & $\mathrm{n}=114$ & $\mathrm{n}=210$ & \\
\hline \multicolumn{5}{|l|}{ At 3-month follow-up } \\
\hline Nonproblematic alcohol use & $9.9^{\mathrm{a}}$ & $11.4^{\mathrm{a}}$ & $11.0^{\mathrm{a}}$ & \multirow[t]{2}{*}{$\left(\chi^{2}\right) 0.913$} \\
\hline Lower level of alcohol use ${ }^{1}$ & $34.9^{\mathrm{a}}$ & $47.4^{\mathrm{b}}$ & $36.2^{\mathrm{a}}$ & \\
\hline Unchanged level of alcohol use & $64.5^{\mathrm{a}}$ & $50.9^{\mathrm{b}}$ & $63.3^{\mathrm{a}}$ & \multirow[t]{2}{*}{$\left(\chi^{2}\right) 0.132$} \\
\hline Higher level of alcohol use & $0.7^{\mathrm{a}}$ & $1.8^{\mathrm{a}}$ & $0.5^{\mathrm{a}}$ & \\
\hline \multicolumn{5}{|l|}{ At 6-month follow-up } \\
\hline Nonproblematic alcohol use & $9.2^{\mathrm{a}}$ & $14.0^{\mathrm{a}}$ & $11.4^{\mathrm{a}}$ & \multirow[t]{2}{*}{$\left(\chi^{2}\right) 0.470$} \\
\hline Lower level of alcohol use ${ }^{1}$ & $30.3^{\mathrm{a}}$ & $49.1^{\mathrm{b}}$ & $37.1^{\mathrm{a}}$ & \\
\hline Unchanged level of alcohol use & $65.8^{\mathrm{a}}$ & $47.4^{\mathrm{b}}$ & $62.9^{\mathrm{a}}$ & \multirow[t]{2}{*}{$\left(\chi^{2}\right) 0.001$} \\
\hline Higher level of alcohol use & $3.9^{\mathrm{b}}$ & $3.5^{\mathrm{b}}$ & $0.0^{\mathrm{a}}$ & \\
\hline \multicolumn{5}{|l|}{ At 12 -month follow-up } \\
\hline Nonproblematic alcohol use & $11.8^{\mathrm{a}}$ & $14.9^{\mathrm{a}}$ & $16.2^{\mathrm{a}}$ & \multirow[t]{2}{*}{$\left(\chi^{2}\right) 0.505$} \\
\hline Lower level of alcohol use ${ }^{1}$ & $32.9^{\mathrm{a}}$ & $50.0^{\mathrm{b}}$ & $37.1^{\mathrm{a}}$ & \\
\hline Unchanged level of alcohol use & $63.2^{\mathrm{a}}$ & $45.6^{\mathrm{b}}$ & $62.9^{\mathrm{a}}$ & \multirow[t]{2}{*}{$\left(\chi^{2}\right) 0.001$} \\
\hline Higher level of alcohol use & $3.9^{\mathrm{b}}$ & $4.4^{\mathrm{b}}$ & $0.0^{\mathrm{a}}$ & \\
\hline
\end{tabular}

Differing superscripts denote a significant difference at the 0.05 level. ${ }^{1}$ Includes change to nonproblematic alcohol use.

sumption category. In contrast, among those allocated to use Alkoholhjalpen.se, $2.1 \%$ increased their use, while none of the control group participants increased their use $\left(\chi^{2}=10.431 ;\right.$ d.f. $\left.=4 ; \mathrm{p}=0.034\right)$. All pairwise comparisons were significant.

\section{Discussion}

The aim of this Web-based RCT was to investigate the effects of a brief screening and feedback intervention for problematic alcohol use, eScreen.se, and a CBTbased extended self-help program for problematic alco- hol use, Alkoholhjalpen.se, in comparison to assessment only. The hypothesis tested was that the brief intervention and the extended CBT-based program would both be associated with a larger decrease in alcohol use than assessment only. A secondary hypothesis tested was that the extended CBT-based program would be associated with a larger decrease in alcohol use than the brief intervention. The results showed that the individuals recruited had high AUDIT scores on average, corresponding to probable dependence on alcohol ( $\geq 20$ AUDIT points).

A decrease in alcohol consumption and alcohol-related problems occurred in all three groups in the first 
Table 4. Proportions (\%) of participants in the PP model who changed to a clinically different level of alcohol use at 3-, 6- and 12-month follow-up among those who accessed any other intervention during the study period and among those who did not access any other intervention

\begin{tabular}{|c|c|c|c|c|}
\hline & eScreen.se & Alkoholhjalpen.se & Control & $\mathrm{p}$ \\
\hline Accessed any other intervention & $\mathrm{n}=44$ & $\mathrm{n}=34$ & $\mathrm{n}=59$ & \\
\hline \multicolumn{5}{|l|}{ At 3-month follow-up } \\
\hline Nonproblematic alcohol use & $6.8^{\mathrm{a}}$ & $14.7^{\mathrm{a}}$ & $16.9^{\mathrm{a}}$ & \multirow{2}{*}{$\left(\chi^{2}\right) 0.307$} \\
\hline Lower level of alcohol use ${ }^{1}$ & $45.5^{\mathrm{b}}$ & $76.5^{\mathrm{a}}$ & $52.5^{\mathrm{a}, \mathrm{b}}$ & \\
\hline Unchanged level of alcohol use & $52.3^{\mathrm{b}}$ & $23.5^{\mathrm{a}}$ & $47.5^{\mathrm{b}}$ & \multirow[t]{2}{*}{$\left(\chi^{2}\right) 0.044$} \\
\hline Higher level of alcohol use & $2.3^{\mathrm{a}}$ & $0.0^{\mathrm{a}}$ & $0.0^{\mathrm{a}}$ & \\
\hline \multicolumn{5}{|l|}{ At 6-month follow-up } \\
\hline Nonproblematic alcohol use & $6.8^{\mathrm{a}}$ & $17.6^{\mathrm{a}}$ & $15.3^{\mathrm{a}}$ & \multirow[t]{2}{*}{$\left(\chi^{2}\right) 0.305$} \\
\hline Lower level of alcohol use ${ }^{1}$ & $40.9^{\mathrm{b}}$ & $73.5^{\mathrm{a}}$ & $57.6^{\mathrm{a}, \mathrm{b}}$ & \\
\hline Unchanged level of alcohol use & $50.0^{\mathrm{a}}$ & $23.5^{\mathrm{a}}$ & $42.4^{\mathrm{a}}$ & \multirow[t]{2}{*}{$\left(\chi^{2}\right) 0.012$} \\
\hline Higher level of alcohol use & $9.1^{\mathrm{b}}$ & $2.9^{\mathrm{b}}$ & $0.0^{\mathrm{a}}$ & \\
\hline \multicolumn{5}{|l|}{ At 12 -month follow-up } \\
\hline Nonproblematic alcohol use & $15.9^{\mathrm{a}}$ & $14.7^{\mathrm{a}}$ & $23.7^{\mathrm{a}}$ & \multirow[t]{2}{*}{$\left(\chi^{2}\right) 0.463$} \\
\hline Lower level of alcohol use ${ }^{1}$ & $47.7^{\mathrm{a}}$ & $73.5^{\mathrm{a}}$ & $54.2^{\mathrm{a}}$ & \\
\hline Unchanged level of alcohol use & $43.2^{\mathrm{b}}$ & $20.6^{\mathrm{b}}$ & $45.8^{\mathrm{a}}$ & \multirow[t]{2}{*}{$\left(\chi^{2}\right) 0.024$} \\
\hline Higher level of alcohol use & $9.1^{\mathrm{a}}$ & $5.9^{\mathrm{a}}$ & $0.0^{\mathrm{a}}$ & \\
\hline Did not access any other intervention & $\mathrm{n}=108$ & $\mathrm{n}=80$ & $\mathrm{n}=151$ & \\
\hline \multicolumn{5}{|l|}{ At 3-month follow-up } \\
\hline Nonproblematic alcohol use & $11.1^{\mathrm{a}}$ & $10.0^{\mathrm{a}}$ & $8.6^{\mathrm{a}}$ & \multirow[t]{2}{*}{$\left(\chi^{2}\right) 0.796$} \\
\hline Lower level of alcohol use ${ }^{1}$ & $30.6^{\mathrm{a}}$ & $35.0^{\mathrm{a}}$ & $29.8^{\mathrm{a}}$ & \\
\hline Unchanged level of alcohol use & $69.4^{\mathrm{a}}$ & $62.5^{\mathrm{a}}$ & $69.5^{\mathrm{a}}$ & \multirow{2}{*}{$\left(\chi^{2}\right) 0.365$} \\
\hline Higher level of alcohol use & $0.0^{\mathrm{a}}$ & $2.5^{\mathrm{a}}$ & $0.7^{\mathrm{a}}$ & \\
\hline \multicolumn{5}{|l|}{ At 6-month follow-up } \\
\hline Nonproblematic alcohol use & $10.2^{\mathrm{a}}$ & $12.5^{\mathrm{a}}$ & $9.90^{\mathrm{a}}$ & \multirow[t]{2}{*}{$\left(\chi^{2}\right) 0.821$} \\
\hline Lower level of alcohol use ${ }^{1}$ & $25.9^{\mathrm{a}}$ & $38.8^{\mathrm{a}}$ & $29.1^{\mathrm{a}}$ & \\
\hline Unchanged level of alcohol use & $72.2^{\mathrm{a}}$ & $57.5^{\mathrm{a}}$ & $70.9^{\mathrm{a}}$ & \multirow[t]{2}{*}{$\left(\chi^{2}\right) 0.049$} \\
\hline Higher level of alcohol use & $1.9^{\mathrm{a}, \mathrm{b}}$ & $3.8^{\mathrm{b}}$ & $0.0^{\mathrm{a}}$ & \\
\hline \multicolumn{5}{|l|}{ At 12 -month follow-up } \\
\hline Nonproblematic alcohol use & $10.2^{\mathrm{a}}$ & $15.0^{\mathrm{a}}$ & $13.2^{\mathrm{a}}$ & \multirow[t]{2}{*}{$\left(\chi^{2}\right) 0.595$} \\
\hline Lower level of alcohol use ${ }^{1}$ & $26.9^{\mathrm{a}}$ & $40.0^{\mathrm{a}}$ & $30.5^{\mathrm{a}}$ & \\
\hline Unchanged level of alcohol use & $71.3^{\mathrm{a}}$ & $56.3^{\mathrm{a}}$ & $69.5^{\mathrm{a}}$ & $\left(\chi^{2}\right) 0.048$ \\
\hline Higher level of alcohol use & $1.9^{a, b}$ & $3.8^{\mathrm{b}}$ & $0.0^{\mathrm{a}}$ & \\
\hline
\end{tabular}

Differing superscripts denote a significant difference at the 0.05 level. Groups with two superscripts ( ${ }^{a}$, b $)$ indicate that they did not differ from any other group, while the other two groups within the same analysis $\left({ }^{\mathrm{a}}\right.$ and ${ }^{\mathrm{b}}$, respectively) differed from each other. ${ }^{1}$ Includes change to nonproblematic alcohol use.

3 months and remained stable up to 12 months, both in ITT and PP analyses. Several differences in the rate or proportion of decreased consumption and problems were, however, noted between the intervention groups and controls. In the PP analysis, those who accessed Alkoholhjalpen.se had somewhat lower AUDIT-C scores at the 6-month follow-up in comparison to those who accessed eScreen.se and controls, but not at the 3- and 12-month follow-ups. PP analyses also showed that a larger proportion of those who accessed Alkoholhjalpen. se as well as any other interventions during the study pe- riod moved to a lower category of alcohol use at the 3-and 6-month follow-ups, compared to those who accessed eScreen.se and to controls. Somewhat perplexingly, at the 6-month follow-up a significantly larger proportion of those who accessed Alkoholhjalpen.se or eScreen.se, as well as any other intervention, changed to a higher consumption category compared to the controls. Further, at the 6- and 12-month follow-ups, participants that only accessed Alkoholhjalpen.se or eScreen.se and no other intervention changed to a higher consumption category in comparison to controls (where none changed to a higher 
consumption category). The result applying to those who only accessed the randomized intervention was confirmed in the ITT model at the 6-month follow-up.

The finding of a short-term decrease in alcohol consumption and alcohol-related problems, noted at the 3-month follow-up, is consistent with previous research on Web-based interventions for problematic alcohol use $[18,25,28,43-45]$. The stability of decreased alcohol consumption and alcohol-related problems for up to 6 months is also consistent with findings from previous studies [18, 43, 44]. One study has shown increases in scores on such outcome measures after 6 months [19], something that we did not see in this study. However, we did see a very small proportion of transitions to higher categories of alcohol consumption in the two intervention groups at 6 months for those who also accessed other interventions; the same phenomenon occurred at 6and 12-month follow-ups among those who did not access other interventions. We can only speculate that exploration of one's own alcohol consumption at both these MI-inspired sites may lead to behavior changes in an unhealthy direction, given the autonomy users are encouraged to exercise. Such behavior change in the 'wrong' direction may be more likely to occur in the absence of a treatment provider who selectively reflects change talk in the client [46]. A Dutch study showing increased reduction of alcohol consumption among participants in therapist-supported Web-based self-help compared to Webbased self-help [23], suggests that therapist support may be an important booster to self-help sites, in the direction of improved health outcomes. It may be that one 'side effect' of openly available Web-based self-help programs is negative change among a certain small proportion of participants; accepting this cost may be an acceptable side effect given the large proportion of users who change in a positive direction.

All of the significant differences found in this study point in the same direction, namely that accessing Alkoholhjalpen.se is more effective for reducing alcohol use than accessing Web-based brief intervention (eScreen.se) or online assessment only. These findings are consistent with the results from a meta-analysis [17], with the results from a recent study showing better 3- and 6-month alcohol outcomes among individuals using a CBT- and MIbased Internet service (similar to Alkoholhjalpen.se) in comparison to a wait-list control group [23], and also with the results from a recent randomized trial showing that an extended Internet-based intervention was more effective for reducing alcohol consumption than a brief screener [29].

Targeting Problematic Alcohol Use with Web-Based Interventions
Nonetheless, our results regarding the effectiveness of the extended CBT-based program Alkoholhjalpen.se must still be regarded as inconsistent. Differences favoring Alkoholhjalpen.se were few in our primary analyses and were not confirmed in our ITT model. The results we report that showed no significant differences between the groups are, in fact, in line with the findings from a large trial recently conducted by Wallace et al. [26] showing no differences at 3-month follow-up between a group receiving an online CBT-based program and a control group where participants were allocated to a Web site with information on the risks of physical harm due to alcohol.

Regarding use of the online brief intervention eScreen. se, all our results consistently showed that the site was about as effective as online assessment only. This finding stands in contrast to the results from the meta-analysis by Riper et al. [17], where online brief interventions were shown to be more effective than assessment only. These results suggest that the personalized feedback on eScreen. se may not have contributed further to a decrease in the measured outcomes. Similar results were found in the meta-analysis by Rooke et al. [13], showing that normative feedback, as a specific component, did not seem to have any impact on the efficacy of Internet-based interventions. Again, however, the results are not completely consistent. The finding that participants accessing eScreen.se spoke with someone about their problematic use, to a significantly greater extent than participants accessing Alkoholhjalpen.se and controls, might be associated with the main eScreen.se recommendation to seek help by speaking to someone about problematic use. Whether or not the personalized feedback given in eScreen.se actually contributes anything to behavior change, this type of brief intervention could still serve as a gateway to natural recovery or initiating face-to-face treatment [47-49]. Our reasoning is that individuals seeking help at random on the Web can test themselves with professional screening instruments; this is what the control group participants in our study were able to do, with concurrent reductions in their problematic alcohol use. Such a service is otherwise available only through contacting a professional treatment provider, something these individuals may well be reluctant to do - both due to the stigma involved as well as because they may not be convinced enough that they actually have a problem, at least at the time they access the Web-based service. The realization, via a service such as eScreen.se, that one does indeed have a problem that requires action, can give impetus to self-recovery via bibliotherapy, self-help groups 
or engaging significant others in support activities. Or, of course, the individual can seek out face-to-face professional treatment.

The apparent lack of differences in efficacy shown in the ITT analyses of this trial suggests that the decrease at 3 months as well as the continued stability of the decrease might result from factors other than the interventions investigated. First, all participants, irrespective of randomization group, were assessed with the AUDIT up to four times during the study period. Simple screening with the AUDIT is known to lead to a decrease in alcohol use [50, 51], and it could be that the active ingredient in all three conditions was identifying the problem, increasing awareness and stimulating reflection about drinking. Second, all individuals recruited to this trial were in some way help-seekers since we recruited them while they were searching for information about alcohol on the Internet. This could mean that the process of change began long before these individuals were recruited into the trial. Third, the regression towards the mean phenomenon could explain some of the decrease in alcohol use we saw upon reassessment in all 3 groups, given that all study participants were recruited based on their initial problematic alcohol use.

\section{Limitations}

Although the large attrition rate in this study was similar to other studies in the research field [16] as well as to dropout from face-to-face treatment [52], the attrition is certainly still a significant limitation that does not allow generalizability of our results to a broader population of Internet help-seekers. High attrition rates may, however, be a reality in studies with online recruitment and follow-up, particularly when there is no participant payment or reward. Conducting analyses according to different models for inclusion was our attempt to assess the impact of selective attrition on our results. Another limitation of this study is that the control group was told, for ethical reasons, that earlier research has shown that responding to questions about alcohol and drug use has an effect on reduction of such use. This statement might have served as an intervention per se and potentially lead to a decrease in alcohol use for the controls. This in its turn could have introduced a bias in the study results and led to an underestimation of the differences between the intervention groups and the controls. Yet another limitation in this study was that the interventions tested are freely available and open to all interested individuals from the general population and not restricted for the use by the study participants. This has also introduced a bias for the study results since our analyses showed that some eScreen.se users and controls also used Alkoholhjalpen.se alongside this study; this might contribute to an underestimation of the efficacy of Alkoholhjalpen.se. A final limitation is associated with our use of outcome measures. Since the AUDIT focuses on alcohol-related problems over the past year, our secondary outcome measures overlap one another timewise at the 3-and 6-month follow-ups, although not at baseline and the 12-month follow-up. In order to accommodate this, we chose to use the AUDIT-C as our primary outcome measure. With its focus on current consumption, we felt it would be more suitable, although we were aware that it has lower reliability than the full AUDIT. Our future research will include other concurrent measures of alcohol consumption.

\section{Future Research}

In this trial, we collected no information on what made participants change their problematic alcohol behavior. In order to increase understanding of how participants allocated to Web-based interventions actually use them, and what importance they ascribe to the interventions for their recovery, qualitative research is necessary. Furthermore, measuring the exact contribution of particular components should be built into quantitative research, for example using a multiphase optimization strategy [53]. Exploring dose-response effects could also contribute to a greater understanding of Web-based interventions and mechanisms of behavior change. The small but significant proportion of participants allocated to the intervention groups who changed to a clinically higher level of alcohol use pinpoints the fact that potential risks and side effects of such interventions should also be taken into account in future studies. Finally, cost-efficacy is often brought up as an important advantage of Internet-based interventions, but few studies actually explore this issue [54-56], particularly in comparison with face-to-face treatment.

\section{Conclusions}

The types of interventions offered via eScreen.se and Alkoholhjalpen.se have previously been channeled through professional treatment providers. Problematic alcohol users have thus needed to recognize their problematic use and contact a professional treatment provider in order to gain access to evidence-based help. Through Web-based interventions of the type tested in this study, 
help is available to virtually unlimited numbers of individuals, at any stage in their recovery process. We found that all three groups reduced their use after 3 months and generally maintained their reduction over 12 months. However, we found indications that a CBT-based extended self-help intervention was more effective in reduction consumption at 6 months, as well as in contributing to participant movement to categories of lower alcohol use at 6 and 12 months, particularly when the participants accessed additional interventions. Even though the extended intervention led to better results, brief intervention in the form of simple screening with feedback can also provide valuable access to evidencebased screening tests associated with health-related behavior change. In sum, this study contributes data that support earlier findings that extended self-help can be more effective than brief screening and feedback interventions. Nonetheless, the phenomenon of access to additional interventions that we highlight in this study clearly indicates that more research is needed for a greater understanding of how individuals actually use Webbased interventions, and exactly how such use affects their alcohol-related behavior.

\section{Acknowledgements}

This work was supported by the National Board of Health and Welfare's Institute for Method Development in Social Work, the Swedish National Drug Policy Coordinator (grant No. MOB 2382006-32) and the Stockholm Center for Dependency Disorders. We thank the anonymous reviewers for highly valuable comments on earlier versions of the manuscript.

\section{References}

1 World Health Organization: Global health risks: mortality and burden of disease attributable to selected major risks. Geneva, World Health Organization, 2009.

$\checkmark 2$ Kaner E, et al: Effectiveness of brief alcohol interventions in primary care populations. Cochrane Database Syst Rev 2007; CD004148.

-3 Moyer A, et al: Brief interventions for alcohol problems: a meta-analytic review of controlled investigations in treatment seeking and non-treatment-seeking populations. Addiction 2002;97:279-292.

4 Raistrick D, Heather V, Godfrey C: Review of the Effectiveness of Treatment for Alcohol Problems. London, National Treatment Agency for Substance Misuse, 2006.

5 Levin ME, Lillis J: Substance abuse; in O'Donohue WT, Draper C (eds): Stepped Care and e-Health: Practical Applications to Behavioral Disorders. New York, Springer, 2011, pp 115-136.

6 Cunningham JA, Blomqvist J: Examining treatment use among alcohol-dependent individuals from a population perspective. $\mathrm{Al}$ cohol Alcohol 2006;41:632-635.

7 Cunningham JA, Breslina FC: Only one in three people with alcohol abuse or dependence ever seek treatment. Addict Behav 2004;29:221-223.

8 Cunningham JA, et al: Barriers to treatment: why alcohol and drug abusers delay or never seek treatment. Addict Behav 1993;18:347353.

$\checkmark 9$ Fortney J, et al: Factors associated with perceived stigma for alcohol use and treatment among at-risk drinkers. J Behav Health Serv Res 2004;31:418-429.

10 Grant BF: Barriers to alcoholism treatment: reasons for not seeking treatment in a general population sample. J Stud Alcohol 1997;58: 365-371.

11 Khadjesari Z, et al: Can stand-alone computer-based interventions reduce alcohol consumption? A systematic review. Addiction 2011;106:267-282.

12 Newman MG, et al: A review of technologyassisted self-help and minimal contact therapies for drug and alcohol abuse and smoking addiction: is human contact necessary for therapeutic efficacy? Clin Psychol Rev 2011; 31:178-186.

13 Rooke S, et al: Computer-delivered interventions for alcohol and tobacco use: a metaanalysis. Addiction 2010;105:1381-1390.

14 White A, et al: Online alcohol interventions: a systematic review. J Med Internet Res 2010, 12:e62.

15 Vernon ML: A review of computer-based alcohol problem services designed for the general public. J Subst Abuse Treat 2010;38:203211.

16 Cunningham JA, Kypri K, McCambridge J: Use of emerging technologies in alcohol treatment. Alcohol Res Health 2011;33:320-326.

17 Riper H, et al: Effectiveness of E-self-help interventions for curbing adult problem drinking: a meta-analysis. J Med Internet Res 2011; 13:e42.

18 Cunningham JA, et al: A randomized controlled trial of an Internet-based intervention for alcohol abusers. Addiction 2009; 104: 2023-2032.

19 Cunningham JA, et al: Twelve-month followup results from a randomized controlled trial of a brief personalized feedback intervention for problem drinkers. Alcohol Alcohol 2010; 45:258-262.

20 Doumas DM, Hannah E: Preventing highrisk drinking in youth in the workplace: a
Web-based normative feedback program. J Subst Abuse Treat 2008;34:263-271.

21 Boon B, et al: Curbing alcohol use in male adults through computer generated personalized advice: randomized controlled trial. J Med Internet Res 2011;13:e43.

22 Hansen ABG, et al: Internet-based brief personalized feedback intervention in a nontreatment-seeking population of adult heavy drinkers: a randomized controlled trial. J Med Internet Res 2012;14:e98.

23 Blankers M, Koeter MWJ, Schippers GM: Internet therapy versus Internet self-help versus no treatment for problematic alcohol use: a randomized controlled trial. J Consult Clin Psychol 2011;79:330-341.

24 Riper $\mathrm{H}$, et al: Translating effective Webbased self-help for problem drinking into the real world. Alcohol Clin Exp Res 2009;33:1-8.

25 Riper H, et al: Web-based self-help for problem drinkers: a pragmatic randomized trial. Addiction 2008; 103:218-227.

26 Wallace P, et al: On-line randomized controlled trial of an Internet based psychologically enhanced intervention for people with hazardous alcohol consumption. PLoS One 2011;6:e14740.

27 Hester RK, Delaney HD, Campbell W: ModerateDrinking.com and moderation management: outcomes of a randomized clinical trial with non-dependent problem drinkers. J Consult Clin Psychol 2011;79:215-224.

28 Hester RK, et al: A Web application for moderation training: initial results of a randomized clinical trial. J Subst Abuse Treat 2009;37: 266-276.

29 Cunningham JA: Comparison of two Internet-based interventions for problem drinkers: randomized controlled trial. J Med Internet Res 2012;14:e107.
Targeting Problematic Alcohol Use with Web-Based Interventions 
30 Saunders JB, et al: Development of Alcohol Use Disorders Identification Test (AUDIT): WHO Collaborative Project on Early Detection of Persons with Harmful Alcohol Consumption - II. Addiction 1993;88:791804.

31 Berman AH, et al: Evaluation of the Drug Use Disorders Identification Test (DUDIT) in criminal justice and detoxification settings and in a Swedish population sample. Eur Addict Res 2005;11:22-31.

-32 Sinadinovic K, Wennberg P, Berman AH: Targeting problematic users of illicit drugs with Internet-based screening and brief intervention: a randomized controlled trial. Drug Alcohol Depend 2012;126:42-50.

-33 Sinadinovic K, Wennberg P, Berman AH: Internet-based screening and brief intervention for illicit drug users: a randomized controlled trial with 12-month follow-up. J Stud Alcohol Drugs, 2014;75:313-318.

34 GraphPad Software Inc. http://www.graph pad.com/quickcalcs/index.cfm. 2005 (cited October 1, 2009).

35 Berman AH, Brisendal C: Constructive Counseling on Drugs and Alcohol with the DUDIT-E and the Alcohol-E (in Swedish). Stockholm, Gothia Förlag, 2011.

36 Berman AH, et al: The self-report Drug Use Disorders Identification Test-Extended (DUDIT-E): reliability, validity, and motivational Index. J Subst Abuse Treat 2007;32 357-369.

37 Sinadinovic K, et al: Internet-based assessment and self-monitoring of problematic alcohol and drug use. Addict Behav 2010;35: 464-470.

38 Miller WR, Rollnick S: Motivational Interviewing: Preparing People for Change, ed 2. New York, Guilford, 2002.
39 Berman AH, Wennberg P, Källmén H: AUDIT and DUDIT - Identifying Problematic Alcohol and Drug Use (in Swedish). Stockholm, Gothia Förlag, 2012.

40 Esterling BA, et al: Empirical foundations for writing in prevention and psychotherapy: mental and physical health outcomes. Clin Psychol Rev 1999;19:79-96.

41 Bush K, et al: The AUDIT alcohol consump tion questions (AUDIT-C): an effective brief screening test for problem drinking. Ambulatory Care Quality Improvement Projekt (ACQUIP). Arch Int Med 1998;158:17891795.

42 Faul F, et al: Statistical power analyses using G*Power 3.1: tests for correlation and regression analyses. Behav Res Methods 2009;41: 1149-1160.

43 Koski-Jännes A, Cunningham JA, Tolonen K: Self-assessment of drinking on the Internet 3-, 6- and 12-month follow-ups. Alcohol Alcohol 2009;44:301-305.

44 Pemberton MR, et al: Evaluation of two Webbased alcohol interventions in the U.S. military. J Stud Alcohol Drugs 2011;72:480-489.

45 Postel MG, et al: Effectiveness of a Web-based intervention for problem drinkers and reasons for dropout: randomized controlled trial. J Med Internet Res 2010;12:e68.

46 Miller WR, Rollnick S: Motivational Interviewing: Helping People Change, ed 3. New York, Guilford Press, 2013.

47 Blomqvist J: Paths to recovery from substance misuse: change of lifestyle and the role of treatment. Subst Use Misuse 1996;31:18071852 .
8 Blomqvist J: Treated and untreated recovery from alcohol misuse. Environmental influences and perceived reasons for change. Subst Use Misuse 1999;34:1371-1406.

49 Blomqvist J: Recovery with and without treatment: a comparison of resolutions of alcohol and drug problems. Addict Res Theory 2002; 10:119-158.

50 Kypri K, et al: Assessment may conceal therapeutic benefit: findings from a randomized controlled trial for hazardous drinking. Addiction 2006;102:62-70.

51 McCambridge J, Day M: Randomized controlled trial of the effects of completing the Alcohol Use Disorders Identification Test questionnaire on self-reported hazardous drinking. Addiction 2007;103:241-248.

52 Postel MG, et al: Characteristics of problem drinkers in E-therapy versus face-to-face treatment. Am J Drug Alcohol Abuse 2011; 37:537-542.

53 Collins LM, Murphy SA, Strecher VJ: The Multiphase Optimization Strategy (MOST) and the Sequential Multiple Assignment Randomized Trial (SMART): new methods for more potent eHealth interventions. Am J Prevent Med 2007;32(suppl 5):S112-S118.

54 Budman SH: Behavioral health care dot-com and beyond: computer-mediated communications in mental health and substance abuse treatment. Am Psychol 2000;55:1290-1300.

55 Smit F, et al: Modeling the cost-effectiveness of health care systems for alcohol use disorders: how implementation of eHealth interventions improves cost-effectiveness. J Med Internet Res 2011;13:e56.

56 Blankers M, et al: Economic evaluation of Internet-based interventions for harmful alcohol use alongside a pragmatic randomized controlled trial. J Med Internet Res 2012;14:e134. 